\title{
Estimation and Assessment of Drought in North China based on Evapotranspiration Drought Index and Remote Sensing Data
}

\author{
Jiahua Zhang ${ }^{1,2}$ \\ ${ }^{1}$ College of Geosciences, \\ Yangtze River University, \\ Wuhan, 413000, China; \\ ${ }^{2}$ Chinese Academy of Meteorological Sciences, \\ Beijing, 100081, China
}

\author{
Fengmei $\mathrm{Yao}^{3^{*}}$, Xiaolu Shao ${ }^{3}$ \\ ${ }^{3}$ Key Laboratory of Computational Geodynamics of CAS, \\ Beijing 100049, China; \\ yaofm@ucas.ac.cn
}

\begin{abstract}
Daily actual evapotranspiration is estimated based on surface net radiation, vegetation index, average air temperature and daily air temperature range using satellite remote sensing data and routine meteorological data. Also, the estimated actual evapotranspiration (ET) is compared and validated with measured ET using eddy covariance method at luancheng station. Besides, the temporal and spatial variation of actual evapotranspiration and its impact factors are analysed qualitatively. According to the evapotranspiration through the ET model correlates well with the measured ET and the estimation is acceptable for assessing the drought conditions at large area of scales. In addition, the EDI anomaly can reflect a higher spatial resolution of drought pattern and is reliable in the indication and judgment of drought.
\end{abstract}

Keywords-actual evapotranspiration; evapotranspiration drought index; North China; remote sensing

\section{INTRODUCTION}

Under global climatic change, the extreme climatic events such as frequency and intensity of drought disaster significantly increased in the global and regional scales [1, $2]$. Besides, the drought has a wide range of impact and serious economic losses. Therefore, assessment and monitoring of drought is important for the understanding affection of climate change and disaster mitigation [3]. To study the features of the occurrence and development of drought, some researcher developed a series of drought indexes $[4,5]$. Considering the precipitation, water supply, water demand, actual evapotranspiration, potential evapotranspiration and other factors, Palmer(1965) has set up a meteorological drought index (Palmer Drought Severity Index, PDSI) based on water balance [6]. The index is widely used in the drought assessment and the analysis of temporal and spatial distribution of drought in many countries. McKee et al. (1993) has proposed the Standardized Precipitation Index (SPI) based on precipitation, reflecting the intensity and duration of drought by the study on the statistical distribution of rainfall [7]. In recent years, the drought monitoring method has been developed using satellite remote sensing information. Wang and Liang (2008) developed a simple semi-empirical statistics algorithm for calculating the actual evapotranspiration (ET) driven by net radiation, vegetation index, air temperature and soil moisture [8], and the simulation results are very close to the ET values estimated by Second Global Soil Wetness Project (GSWP-2). The ET model took the atmosphere, vegetation and soil and other factors into account. The greatest advantage is that less meteorological parameters are required and they are easy to access. Also, this greatly improves the spatial resolution by the use of remote sensing data. In this paper, firstly, we use the surface measured data to verify the simulation results of the ET model, then we analysis the spatial and temporal distribution of actual evapotranspiration and its impact parameter. Finally, we study the drought distribution in North China using the EDI index based on the ET model and PET model, and do comparison with other drought index, and thus provide a basis for drought monitoring and assessment of large area.

\section{DATA AND METHODS}

\section{A. Model input data}

In this paper, grid point data used include: (1) radiation data of Global Energy and Water Cycle Experiment-Surface Radiation Budget (GEWEX-SRB). Radiation flux contain the upward-downward shortwave and long wave radiation flux of the top of atmosphere and the ground with horizontal resolution $1^{\circ} \times 1^{\circ}$. (2) Normalized Difference Vegetation Index (NDVI) data: MODIS NDVI composite products with $1-\mathrm{km}$ spatial resolution and 16-day temporal resolution are used here (i.e. MOD13A2). (3) air temperature data: the latest version of the reanalysis data ERA-Interim in the height of $2 \mathrm{~m}$ from ECMWF(European Centre for MediumRange Weather Forecasts):daytime average air temperature 、 daily maximum and minimum air temperature with resolution is $0.75^{\circ} \times 0.75^{\circ}$. The above information is uniformly interpolated to $0.25^{\circ} \times 0.25^{\circ}$ grid point.

\section{B. Ground validation data}

The validation site of the actual evapotranspiration is located in Luancheng agricultural ecosystem experimental station of Chinese academy of science $\left(37^{\circ} 53^{\prime} \mathrm{N}\right.$ 、 $114^{\circ} 41^{\prime} \mathrm{E}$ ), the altitude is $50.1 \mathrm{~m}$, it is semi-arid and semi- 
humid monsoon climate at warm temperate zone. The vegetation type of Luancheng Station is deciduous broadleaved forest, its cropping system is winter wheat-corn double cropping. Eddy covariance method is gradually accepted in reliability, with it being widely used in the aspects of water vapor flux and energy transmission, so the estimated evapotranspiration in this study is compared with the actual daily evapotranspiration using eddy covariance method at Luancheng Station in 2008. The distribution of drought in North China is compared and analyzed from the site data as follows: selecting equably better quality temperature and precipitation daily observation data to calculate Palmer index and precipitation anomaly percentage in 84 sites in North China, it is used for contrastive analysis and aided verification of drought pattern in North China.

\section{Evapotranspiration Model}

\section{1) Actual Evapotranspiration ET}

Actual evapotranspiration is a key link of water cycle and determines the water, heat transmission in the soilvegetation-atmosphere system. To reduce the input parameters of ET model, Wang et al. (2008) developed the semi-empirical statistical model for estimating evapotranspiration, given as follows:

$$
E T=R_{\mathrm{n}}\left[0.1440+0.6495 \mathrm{NDVI}+0.009\left(_{a}-0.016 \$ T_{\max }-T_{\min }\right)\right]
$$

Where, $R_{n}$ is surface net radiation $\left(\mathrm{Wm}^{-2}\right)$, NDVI is the normalized difference vegetation index, $T_{a}$ is the daytime average air temperature, $T_{\max }$ and $T_{\min }$ are daily maximum and minimum air temperature respectively, the ET is actual evapotranspiration flux or latent heat flux $\left(\mathrm{Wm}^{-2}\right)$. Because soil moisture has a potentially important influence on evapotranspiration, the parameterization of this ET model includes the influence of soil moisture by considering the different of daily surface temperature changes or daily air temperature changes. Converts actual evapotranspiration flux ET to daily actual evapotranspiration $\mathrm{E}_{\text {daily }}\left(\mathrm{mmd}^{-1}\right)$, as follows:

$$
E_{\text {daily }}=\frac{86400 \times E T}{\lambda}
$$

Where, $E_{\text {daily }}$ is daily actual evapotranspiration, $\lambda$ is latent heart of vaporization of water $\left(\mathrm{Jkg}^{-1}\right)$, it can be obtained by below:

$$
\lambda=\left(2.501-0.002361 \times T_{a}\right) \times 10^{6}
$$

Where, $\mathrm{T}_{\mathrm{a}}$ is the daytime average air temperature.

\section{2) Potential Evapotranspiration PET}

PET represents the ideal evaporation rate of capturing response to forcing variables if soil moisture is unlimited in certain weather conditions. We adopted Hargreaves's method (2003) to estimate PET here [9]:

$$
P E T=0.0023 R_{\mathrm{a}}\left(T_{\text {mean }}+17.8\right) \sqrt{T_{\text {max }}-T_{\text {min }}}
$$

Were, $\mathrm{R}_{\mathrm{a}}$ is the extra-terrestrial solar incident radiation $\left(\mathrm{Wm}^{-2}\right), \mathrm{T}_{\max }$ and $\mathrm{T}_{\min }$ are daily maximum and minimum air temperature respectively, $\mathrm{T}_{\text {mean }}$ is daily mean air temperature, and $T_{\text {mean }}=\left(T_{\max }-T_{\min }\right) / 2$. PET is potential evapotranspiration flux. Converts potential evapotranspiration flux PET to daily potential evapotranspiration $\mathrm{E}_{\mathrm{p} \text { daily }}$, as follows:

$$
E_{p_{\text {daily }}}=\frac{86400 \times P E T}{\lambda}
$$

Where, $E_{\text {pdaily }}$ is daily potential evapotranspiration, $\lambda$ is latent heart of vaporization of water, it can be obtained by the equation (3).

\section{3) Surface Net Radiation Rn}

Surface Net Radiation is motive power of ground energy, material conveying and exchange process, major factor of climate formation and climate change. $R_{n}$ can be expressed as:

$$
R_{n}=R_{s} \downarrow-R_{s} \uparrow+R_{L} \downarrow-R_{L} \uparrow
$$

Where, $R_{s} \downarrow$ and $R_{s} \uparrow$ are surface downward and upward shortwave radiation respectively, $\mathrm{R}_{\mathrm{L}} \downarrow$ and $\mathrm{R}_{\mathrm{L}} \uparrow$ are surface downward and upward longwave radiation respectively.

We used the Penman-Monteith formula to calculate reference crop evapotranspiration which recommended from FAO (Food and Agriculture Organization) to estimate net radiation [10], and take it as input parameters of actual evapotranspiration model. The formula is as below:

$$
\begin{gathered}
R_{n}=R_{n s}-R_{n l} \\
R_{\mathrm{ns}}=(1-\alpha)(a+b n / N) R_{a} \\
R_{n l}=2.45 \times 10^{9}\left(0.1+0.9 \frac{n}{N}\right)\left(0.34-0.14 \sqrt{e_{d}}\right)\left(T_{k x}^{4}+T_{k n}^{4}\right)
\end{gathered}
$$

Where, $R_{n s}$ and $R_{n l}$ is net shortwave and longwave radiation $\left(\mathrm{MJm}^{-2} \mathrm{~d}^{-1}\right)$ respectively; $\mathrm{R}_{\mathrm{a}}$ is astronomical radiation; $a$ is albedo and values 0.23 , $a$ and $b$ values recommended parameters in the formula $(\mathrm{a}=0.25, \mathrm{~b}=$ 0.5 ); $\mathrm{n}$ and $\mathrm{N}$ are the actual sunshine time and the largest astronomical sunshine time $(\mathrm{h})$ respectively; $\mathrm{e}_{\mathrm{d}}$ is the actual water vapour pressure $(\mathrm{kPa}) ; \mathrm{T}_{\mathrm{kr}}$ and $\mathrm{T}_{\mathrm{kn}}$ are the maximum and minimum absolute temperature $(\mathrm{K})$, respectively.

4) 2.3.4 Evaporative Drought Index EDI

EDI, following the evaporative stress index ESI mechanism, is derived as:

$$
E D I=1-\frac{E T}{P E T}
$$

Where, ET and PET are obtained by Eq.(1) and Eq.(4) respectively. In theory, values of EDI vary between 0 and 1 . The more severe drought on the surface of soil means more severe water stress, then the difference between potential evapotranspiration and actual evapotranspiration is greater, i.e., the value of EDI is higher. On the other hand, the moister soil has the lower value of EDI.

To highlight the difference between some year, season, monthly or ten-day EDI index and the corresponding average value for many years, we introduce the EDI anomaly index, it can be represented as:

$$
\Delta E D I(i)=E D I(i)-\frac{1}{\mathrm{n}} \sum_{i=1}^{n} E D I(i)
$$


Where, $i$ represents year.

\section{RESULTS AND ANALYSIS}

A. Correlation between the estimated evapotranspiration and the measured evapotranspiration

The estimated value of actual evapotranspiration ET model is analysed and compared to the measured ET at Luancheng site in North China.

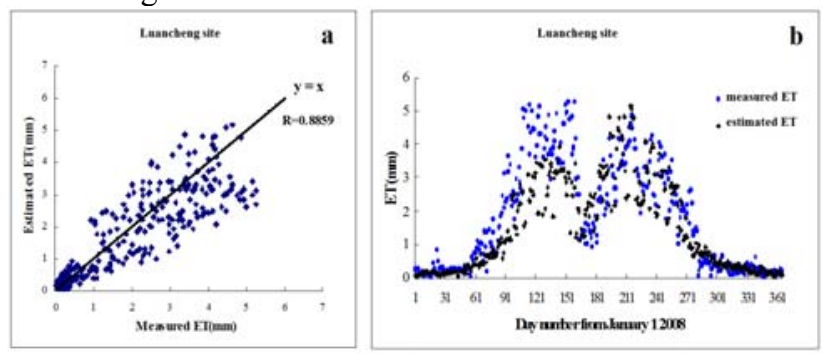

Figure 1. Scatterplots of estimated ET and measured ET(a) and time series of daily estimated ET and measured ET (b) during 2008 at Luancheng site.

Figure 1a showed that the estimated ET and the measured ET is relatively close, and the correlation coefficient is 0.8859 , the root-mean-square error (RMSE) is $0.75 \mathrm{~mm}$. The average bias of the estimated ET and the measured ET is $-0.22 \mathrm{~mm}$, it shows that the estimated ET is less than the measured ET in general, and from Figure $1 \mathrm{~b}$, in the spring (march-may), the estimated ET is basically less than the measured ET, but other month ET and measured ET is relatively close; this is due to the semi-arid areas vulnerable to the impact of surface layer horizontal advection transportation in the spring, the value of the measured ET using eddy covariance method is higher than the actual evapotranspiration.

\section{B. The spatial pattern of EDI $E T$ and the relative parameters}

Figure 2 showed that the average temperature in North China ranges from southeast to northwest, the spatial pattern trend of temperature difference is basically contrary to that of mean temperature. Figure $2 \mathrm{c}$ showed that the NDVI in northwest in North China is lower; while the value of NDVI in south is higher; dark blue area represents part of the Bohai Sea and the Yellow sea, NDVI is negative. The high value area of surface net radiation is located in the northeast of North China, and the low value area is located in the west and south central of North China (Figure 2d). Figure 3 showed that spatial pattern of actual mean ET and EDI in North China during the summer of 2007. The actual ET in North China decreases from southeast to northwest (Figure 3a), which is closely consistent with the distribution characteristics of vegetation index of Figure $2 \mathrm{c}$, i.e. the better vegetation grow, the bigger transpiration is; the actual ET includes both vegetation transpiration and soil evaporation, so another part of the actual ET depends on soil evaporation, and soil evaporation is related to soil water content or soil moisture, the parameterization of the ET model in this article includes the influence of soil moisture by considering the daily temperature difference, i.e. the higher temperature difference means the lower soil moisture, so Figure $3 \mathrm{~b}$ reflected soil moisture decreases from southeast to northwest in North China, this is accordance with the distribution characteristics which the actual ET in northwest is less than that in southeast reflected by Figure 2a in North China. Figure 2b showed that the EDI value increases from southeast to northwest in North China, this is basically opposite with spatial distribution regulation of ET; although EDI value is also associated with potential ET, but for the semi-arid areas, water stress to vegetation is more severe, the actual ET is lower, to a large extent, it reflects the more severe drought in this region, namely, the higher EDI value.
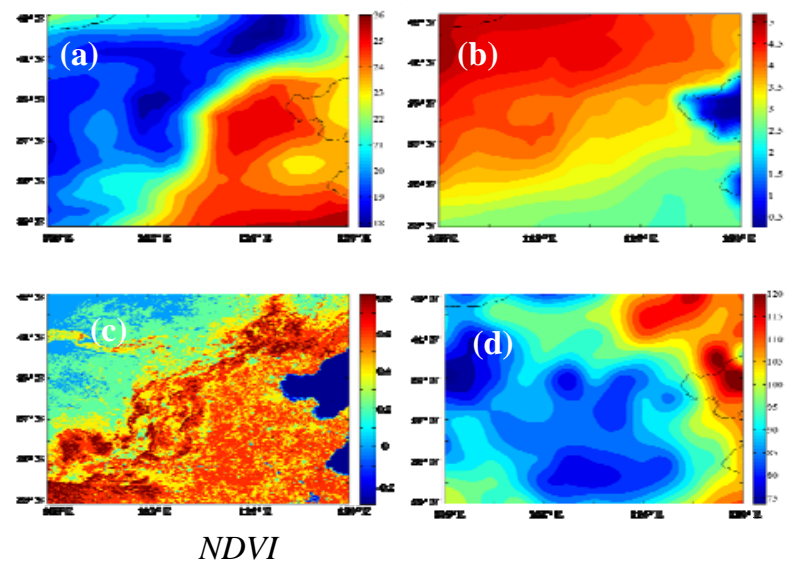

Figure 2. Spatial distribution of daily average air temperature (a)、 air temperature range (b)、 vegetation index(c) and surface net radiation (d) during summer of 2007 in North China.
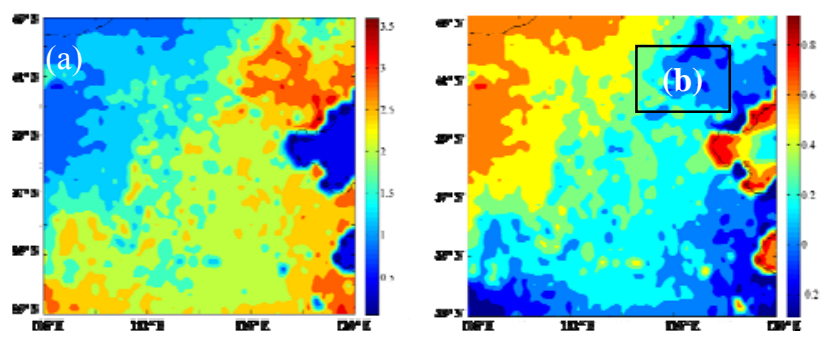

Figure 3. Spatial distribution of actual evapotranspiration (a) and evapotranspiration drought index (b) during summer of 2007 in North China.

\section{The summer drought in North China in 2007}

The average value of EDI for many years can reflect the average degree of dry or wet during the corresponding period of time, but it cannot represent the abnormal dry or wet conditions in some area, so we introduced the EDI anomaly $(\triangle E D I)$ to reflect the severity of the drought somewhere. Take the drought condition in summer of 2007 as example, use the variation of spatial distribution of $\triangle E D I$ from June to August to reflect the evolution of the drought, and compare with the drought instructed by 
PDSI index and percentage of precipitation anomaly. The results showed that in June, the east-north area and westsouth minority region in North China appeared moderate drought, the south-east area is wetter; the drought spatial distribution characteristic displayed by $\triangle E D I$ index is consistent with that displayed by PDSI index and percentage of precipitation anomaly, the difference is that the level of dry or wet displayed by percentage of precipitation anomaly is more severe, PDSI is inferior to the former, this is because percentage of precipitation anomaly is determined only by precipitation, more sensitive to precipitation; $\triangle E D I$ composites these elements of surface net radiation, vegetation index, average air temperature and temperature difference, and contains the soil and vegetation drought index, therefore $\triangle E D I$ index can characterize drought feature more accurately than single meteorological factor.

\section{CONCLUSIONS}

Based on the verification between the estimated ET and the measured ET and the contrast application on $\triangle E D I$ index and PDSI index and percentage of precipitation anomaly in North China, our results showed that the ET value estimated by ET model is closely related to the measured ET, its simulation accuracy for the spatial scales of widespread drought monitoring is available. The temporal variation trend between the measured ET and each impact factors is comparatively unanimous, and there is obvious seasonal variation, among them, the actual ET has best correlation with surface net radiation and NDVI. The actual ET in North China decrease from southeast to northwest, it is basically opposite with spatial distribution regulation of $\triangle E D I$ index, for the semi-arid areas, this is because water stress is severe, the actual ET is lower, to a large extent, which reflects the more severe drought in this region, namely, the higher EDI value. $\triangle E D I$ index not only contains atmosphere drought, but also composites the feedback effect of soil and vegetation on atmosphere drought, hence, the accuracy determining the drought degree is better, and the spatial resolution reflecting drought distribution by $\triangle E D I$ index is obviously higher than that by PDSI index and percentage of precipitation anomaly.

\section{ACKNOWLEDGEMENTS}

This work was supported the Global Change Global Research Key Project of the National Science Plan (No.2010CB951302), the Social Commonweal Meteorological Research Project (No. GYHY201106027), the CAS-TWAS Project of Drought Monitoring in Asia (No.YEYI2701KB), the Hundred Talents Program of Chinese Academy of Sciences (Y24002101A), and the CEODE-Director Program(No.Y2ZZ26101B).

\section{REFERENCES}

[1] Dai, A. G., Trenberth, K. T. \& Qian, T. T., A global dataset of Palmer drought severity index for 1870-2002: Relationship with soil moisture and effects of surface warming. J. Hydrometeorol, 5, pp. 1117-1130, 2004.

[2] Ma, Z., Dry and wet variation and its relationship with regional warming in aird regions of northern China. Chinese J, Geophys. 48(5), pp. 1011-1018, 2005.

[3] Li, D., Yang, T., \& Zhang, X., Causes and impact assessment of autumn and winter low temperature and drought from 2008 to 2009 in Suzhou. Meteorological Monthly,37(5), pp.615-621, 2011.

[4] Hou, Y., He, Y., Liu, Q., Drought monitoring index research. Chinese Journal of Ecology, 26(6) , pp. 892- 897, 2007.

[5] Xie, W., Tian, H., Study on the application of five drought indexes in Anhui province.Meteorological Monthly, 37(4), pp.503-507, 2011.

[6] Palmer, W. C., Meteorological drought US . Weather Bureau Research Paper, 45: 1965.

[7] McKee, T. B., Doesken, N. J., \& Kleist, J., The relationship of drought frequency and duration to time scales. Eighth Conf. on Applied Climatology, Anaheim, CA, Amer. Meteor. Soc., 179-184, 1993.

[8] Wang, K., \& Liang. S., An improved method for estimating global evapotranspiration based on satellite determination of surface net radiation, vegetation index, temperature, and soil moisture. $J$. Hydrometeor., 9, pp. 712-727, 2008.

[9] Hargreaves, G. H., \& Allen, R. G., History and evaluation of Hargreaves evapotranspiration equation. J. Irrig. Drain. Eng., 129, pp.53-63, 2003.

[10] Liu, X., Yu, G., He, H., Research on the calculating of surface net radiation in China. Journal of Natural Resources, 21(1), pp. 139$145,2006$. 